\title{
Global wheat production potentials and management flexibility under the representative concentration pathways
}

Juraj Balkovic, Marijn van der Velde, Rastislav Skalsky, Wei Xiong, Christian Folberth, Nikolay Khabarov, and Alexey Smirnov

International Institute for Applied Systems Analysis, Ecosystems Services and Management, Laxenburg, Austria

(balkovic@iiasa.ac.at)

Global wheat production is strongly linked with food security as wheat is one of the main sources of human nutrition. Increasing or stabilizing wheat yields in response to climate change is therefore imperative. To do so will require agricultural management interventions that have different levels of flexibility at regional level. Climate change is expected to worsen wheat growing conditions in many places and thus negatively impact on future management opportunities for sustainable intensification.

We quantified, in a spatially explicit manner, global wheat yield developments under the envelope of Representative Concentration Pathways (RCP 2.6, 4.5, 6.0 and 8.5) under current and alternative fertilization and irrigation management to estimate future flexibility to cope with climate change impacts. A large-scale implementation of the EPIC model was integrated with the most recent information on global wheat cultivation currently available, and it was used to simulate regional and global wheat yields and production under historical climate and the RCP-driven and bias-corrected HadGEM2-ES climate projections. Fertilization and irrigation management scenarios were designed to project actual and exploitable (under current irrigation infrastructure) yields as well as the climate- and water-limited yield potentials.

With current nutrient and water management, and across all RCPs, the global wheat production at the end of the century decreased from 50 to $100 \mathrm{Mt}$ - with RCP2.6 having the lowest and RCP8.5 the highest impact. Despite the decrease in global wheat production potential on current cropland, the exploitable and climatic production gap of respectively 350 and $580 \mathrm{Mt}$ indicates a considerable flexibility to counteract negative climate change impacts across all RCPs. Agricultural management could increase global wheat production by approximately $30 \%$ through intensified fertilization and 50\% through improved fertilization and extended irrigation if nutrients or water were not limiting. 